\title{
Social and Play Behavior in a Wild Eastern Coyote, Canis latrans, Pack
}

\author{
JONATHAN G. WAY ${ }^{1,2}$ \\ ${ }^{1}$ Science Department, Barnstable High School, 744 West Main Street, Hyannis Massachusetts 02601 USA; e-mail: jon@eastern \\ coyoteresearch.com \\ ${ }^{2}$ Mailing address: Eastern Coyote Research, 89 Ebenezer Rd, Osterville Massachusetts 02655 USA
}
Way, Jonathan G. 2007. Social and play behavior in a wild eastern Coyote, Canis latrans, pack. Canadian Field-Naturalist 121(4): 397-401.

\begin{abstract}
I had close and consistent observations of a wild eastern Coyote pack (Canis latrans) from January 2000 to August 2007. During this time, I obtained 3156 radio-locations on a specific radio-collared breeding male ("Sill") and observed him and/or members of his pack on 375 occasions. The average group size $=3.0 \pm 2.3$ (SD) Coyotes with $1.9 \pm 1.2$ (SD) being adults and $1.1 \pm 1.9$ being pups. Maximal group size involved 12 Coyotes ( 9 pups, 3 adults). During these observations, Coyotes most often behaved in a friendly manner toward each other as indicated by 80 of my observations involving play between pups, and 15 involving play among adult Coyotes. On the evening of 6 July 2007 I observed the breeding male ( $>8$ yr old), his mate ( $>5 \mathrm{yr}$ old), one of their full-sized probable yearlings, and five pups playing intensely for 33 minutes. This paper details social and play behavior from this pack, especially from the 6 July 2007 observation.
\end{abstract}

Key Words: Canis latrans, eastern Coyote, amiable/affiliative interactions, play behavior, Massachusetts.

Although not exclusively a mammalian trait, play is an important social activity for mammals, and especially for carnivores (Bekoff 1972a, b, 1989; Ewer 1973; Rennicke 2007). It is characterized by (1) friendly, non-aggressive (or amiable) intentions; (2) more energy than is strictly necessary; and (3) a typical air of eagerness, excitement, and enjoyment during interactions (Ewer 1973; Bekoff 1974a, b, 1989). Although play is not unknown in adults, it is displayed more commonly in young animals (Bekoff 1978), and provides the means of doing all the things the central nervous system is prepared for without any of the risks inherent in a "real" (e.g., hunting, fighting) situation (Ewer 1973). Hypotheses about the function of play in canids have been reviewed by Bekoff (1974a) and Packard (2003) and include (1) the ability to learn counter-tactics during play that may provide a basis for learning complex social relationships later in life; (2) physical exercise related to aerobic conditioning; (3) development of muscular routines; (4) practice of instincts useful for hunting later in life; (5) a demonstration that "animals that play together, tend to stay together"; i.e., social cohesion; and (6) an indication that it may simply be fun and a pleasurable experience.

In the vast majority of studies on Coyotes (Canis latrans) (and on carnivores in general), play behavior has occurred with juveniles in captivity where researchers can easily observe their study subjects and quantify behavioral observations in a controlled setting (Bekoff 1972a, 1974b, 1978, 1989; Way et al. 2006). Packard (2003) noted that our understanding of Wolf (Canis lupus) social behavior will advance more rapidly when we integrate the information from both captive and field populations, as long as we take great care to recognize the limitations of each perspective and to understand the whole as the sum of the parts. However, few studies have examined the play of Coyotes and Wolves in the wild (Ortega 1988; Mech 1997; Packard 2003). Of these studies, all detailed play behavior was observed only in pups.

For instance, Mech (1997: 75) watched wild Wolf pups in the Arctic play "for about 45 minutes as the pups scrambled back and forth across the snowfield, chasing one another, tackling, sliding, rolling, skidding, and carrying on to a degree I have never seen nor heard of before for any species." Observations of pups playing is a common theme in studies on play behavior in canids, and despite some authors claiming that adult canids play (e.g., Bekoff 1989; Lehner 1978; Packard 2003), there is scant evidence of this in the wild, possibly due to their need for conservation of energy, certainly in harsh climates. In this paper I describe a social, amiable, wild Coyote pack, including observations of the older adults in the pack playing.

\section{Methods}

Research was conducted in an urbanized area (town of Barnstable on Cape Cod) in eastern Massachusetts (see Way et al. 2001, 2002a, 2004). Average human density on the study site was 290 people $/ \mathrm{km}^{2}$ and road density was $4.66 \mathrm{~km}$ of roadway per $\mathrm{km}^{2}$ (Cape Cod Commission 1998*). Observations began on 18 January 2000 when the Coyote "Sill" (ID \# 0003), a 16.8 kg 9-month old male Coyote was captured in a box trap (model 610B, $152.4 \mathrm{~cm} \times 50.8 \mathrm{~cm} \times 66.0 \mathrm{~cm}$, Tomahawk Live Trap Co., Tomahawk, Wisconsin, USA: Way et al. 2002b) in Cotuit (within the town of Barnstable), Massachusetts, and radio-collared as part of an ongoing study of eastern Coyote ecology on Cape Cod (Way et al. 2002a, 2004). Sill was tracked on his natal range (his father, "Kett," ID \# 9805, was also radio-collared) until January 2001 when he dispersed 
and settled into a vacant territory to the immediate east of his natal range in February/March 2001 (see Way $2007^{*}$ for more details). He was the dominant male of that new pack (Newtown/Bog Pack) in Marstons Mills (within the town of Barnstable) from 2002 to 2007, when the study ended.

Tracking protocols were fully described by Way et al. (2002a, 2004). Portable receivers (Custom Electronics, Urbana, Illinois, USA) and hand-held 3-element Yagi antennas were used to radio-track Coyotes both on foot and from a vehicle. Animals were typically homed in on using the loudest-signal method of radio-tracking (Springer 1979). I approached radiocollared Coyotes as closely as possible without disturbing them. I used binoculars, $15-45 \times$ spotting scopes (Bushnell, Overland Park, Kansas, USA), and videocameras when observing Coyotes at den and rendezvous sites (Way et al. 2001, 2003), and spotlighting and headlights when following Coyotes at night with a vehicle (Way et al. 2002a, 2004).

Collared Coyotes were often seen with untagged companion(s), especially when at rendezvous sites (Way 2003). A detailed description (e.g., size, coloration, distinguishing markings, and behavior) of the uncollared animals was made during every direct observation. In this manner, the unmarked Coyotes were identified based on appearance, as described by Way et al. (2002a) and Way (2004). Overall, I identified as many Coyotes as possible from Sill's pack, as well as from other groups within the study area. I classified Coyotes as adults or pups/juveniles. Adults were classified as all full-sized Coyotes and often included yearlings that remained on their natal territory. Pups were born in April (Way et al. 2001) and were classified as such until October, when they approached full body size and became indistinguishable from adults when observed in the field. Due to the logistic difficulties of keeping track of large groups $(\geq 5)$ of Coyotes observed at the same time (especially when they temporarily separated and were all visible at the same time but only one observer was there to monitor them in separate locations), it was necessary to began with this simple coding scheme (pups or adults).

Most of the lengthy sightings were made at two sets of cranberry bog complexes (2-3 bogs at each location; complexes were $1 \mathrm{~km}$ apart) where distant $(\sim 400 \mathrm{~m})$ viewing was possible (Way 2003, 2007*). Sill's pack began using these bogs in summer 2003 following the death of an old female Coyote ("Mole" \#0110) in the pack to their immediate northeast (Way and Strauss 2004; Way 2007*). To avoid autocorrelation (see Way et al. 2004), sightings were separated by $>4 \mathrm{~h}$ from each other. Typically this meant that Coyotes were observed during dawn and/or dusk on a given day with occasional daytime observations $(n \sim 25)$.

Play was defined as the behavior that was performed during social interactions in which there was a decrease in social distance between the interactants, and no evidence of social investigation or of agonistic or passive-submissive behaviors on the part of the members playing, although these actions may occur as derived acts during play (e.g., passive submission during a play bout - Bekoff 1972a, 1974a; Way et al. 2006). Bekoff (1974a) classified play as (1) incorporating various contexts into unpredictable temporal sequences; (2) preceded by a metacommunicative signal (e.g., play initiation); (3) repeated and performed actions in an exaggerated manner; and (4) appearance of being pleasurable to the participants, e.g. a play face (wide open jaws and eyes) is apparent. Included in play were numerous role reversals where more dominant Coyotes allowed lower ranked Coyotes to pin them to the ground; this was never documented during agonistic displays (Way et al. 2006).

I used continuous animal sampling (Martin and Bateson 1986) to record Coyote activity and recorded the behavior (via scan sampling) of as many Coyotes concurrently as I could during my observations. I recorded data into a field notebook and video-camera for later analysis.

\section{Results}

I obtained 3156 radio-locations on Sill and observed him and/or members of his pack 375 times ( $>4$ hours apart) from January 2000 to August 2007. The average Coyote group size during the 375 sightings was $3.0 \pm 2.3(\mathrm{SD})$ Coyotes with $1.9 \pm 1.2$ being adults and $1.1 \pm 1.9$ being pups. Maximal group size observed during an observation involved 12 Coyotes (9 pups, 3 adults), while two sightings involved 10 Coyotes ( 3 adults and 7 pups) and eight sightings involved 9 Coyotes (ranging from 2-7 adults and 2-7 pups). This pack was typical of other eastern Coyote social groups (see Way et al. 2002a, 2003) in that Sill had a mate ("Mange-back", positively identified from 2004/2005 to 2007, having a distinct missing patch of fur on the top of her neck and a large softball-sized bleached-like looking mark on her left rib which looked like a distinct blonde splotch on an otherwise brown body) and those two comprised the breeding pair while the remaining adults appeared to be yearlings, or pack associates, most likely their offspring from the previous year. On any given year there were 3 to 5 adults (including associates/yearlings) and four or more pups. Sill's group was especially visible for the four and a half years from 2003 to 2007 when they adjusted their territory to include two complexes of several cranberry bogs each, formerly used by a pack to their northeast. Although many of the sightings were temporary (e.g., one or two Coyotes observed for 1-2 sec while crossing a road at night), $160(42.7 \%)$ observations occurred at rendezvous sites averaging $44.5 \pm 31.4$ (SD) min (maximum bout $=142 \mathrm{~min}$ ) in duration. These rendezvous site observations produced all of the observations of play detailed below. 
Coyote pups often played with each other during observation bouts $(n=80)$ at the rendezvous sites, which consisted of chasing, wrestling, and self-play (Way et al. 2006). It was very apparent when they were playing because role reversals often occurred where small pups pinned larger, more dominant ones (Rennicke 2007). Also, chasing often involved different combinations of chaser(s) and chasee(s) where close observations indicated open (sometimes panting), relaxed mouths. In all observations, colleagues, some of my students, or the general public (I usually observed from a main road and people frequently stopped to observe with me) agreed with my assessment of play rather than another behavior (e.g., agonistic). On 15 occasions, I observed adult Coyotes play with one another. These were frequently games such as groupchases or wrestling matches where pups also became involved. The only negative interactions that I observed between adults was when one probable yearling pinned another ( $n=9$ observations). I did not observe any aggressive acts directed toward Sill or his mate "Mangeback" but on four occasions Mange-back aggressively pinned another (probable female) Coyote into a passive submission posture. Based on subsequent observations, these Coyotes were likely her yearling daughters.

Sill was a very diligent father and often returned to the rendezvous sites throughout the year. Many of my observations consisted of him and 1-2 others (usually adults) returning from patrolling their territory at night to joining other Coyotes waiting at these sites (i.e., full-sized pups). During the summers of 2005 to 2007, when I positively identified Mange-back as his mate, I more often saw Sill (80\% of sightings) at the rendezvous sites (July-October) with the pups than Mangeback ( $\sim 60 \%$ of sightings involved her). All Coyotes acted submissive to Sill except for Mange-back, who rarely interacted with him, likely because of their familiarity with one another. Yearlings $(n=20$ sightings) and pups $(n=75)$ often greeted Sill in an active submission posture which involved repeated licking of his mouth with exaggerated tail wagging by the intended recipient (Way et al. 2006). Sill frequently regurgitated ( $n=10-12$ observations) to pups when solicited, especially when returning to the rendezvous sites from surrounding areas. In fact, the only negative (agonistic) interactions I observed was when Sill growled at persistent pups ( $\mathrm{n}=10-12$ observations) who repeatedly tried to lick his mouth to try stimulating him to regurgitate. All of the factors detailed herein indicated that Sill was the breeding male of a large, very successful, and amiable eastern Coyote pack.

The evening of 6 July 2007 produced the most memorable observations of amiable and play behavior from this pack. For 33 minutes I observed three adults (out of four in the pack at the time) and five pups from the pack (one of which was later hit and killed by a car on 20 July), including Sill (8 years, 3 months old at the time), Mange-back (likely $>5$ years old), and a yearling male named "White-band" (for a white band running laterally on his tail just posterior to the base) that was the same size as Sill. They were at the northern-most area of the two rendezvous sites (north of the site from Way 2003). At 20:15, I arrived at the rendezvous site and immediately saw eight Coyotes about $250 \mathrm{~m} \mathrm{NW}$ of my location on Bog Road in Marstons Mills. They were at the junction between the northwest part of the east bog and northeast part of the middle bog (three bogs comprised this area west of Bog Road) in an open sand flat (about $25 \times 20 \mathrm{~m}$ ) dubbed "Olivia's" $(\mathrm{O})$ flats for a homeowner's walking trail that leads southeast to this location $\sim 75 \mathrm{~m}$ from her house.

When I arrived, I immediately set up my tripod and spotting scope as the pups were particulary active and running back and forth playing, both play chasing and play wrestling (see Way et al. 2006). At 20:20, Sill walked west about 50-75 $\mathrm{m}$ and bedded in sit1 alert position (Way et al. 2006) on a small $(1.5 \mathrm{~m}$ high) mound of sand, next to a small shed/pumphouse just north of the northcentral part of the central bog. He sat alert and watched the other seven Coyotes from a distance until 20:25, when Mange-back led the five pups to the sand mound where Sill was sitting. To get the pups there, she turned around and faced the pups and took a few steps toward them until they followed her. I was too far away to hear if she called them over or if they just followed her, but she did that two or three times before completing the short trip. Whiteband followed the group west to the sand mound.

After trotting to that location $(\sim 15-20 \mathrm{sec}$.) the pups immediately re-engaged in intense bouts of play chasing and play wrestling. Sill greeted a couple of the pups by licking them but mostly stood up when the group arrived and then proceeded to watch them. At ca. 20:30, Mange-back, which was watching the pups play for ca. 2-3 min, got into the games by pinning a couple of pups. She had a noticeably relaxed play face (Bekoff 1974a, 1974b; Lehner 1978) and jumped back and forth as a couple of pups chased after her. Sill and White-band watched the actions right on the mound and despite pups bumping into Sill, he maintained his vigilance by surveying the area for danger.

At 20:32 Sill became active. He gathered a couple of pups, then trotted east back to the O flats. Mange-back and White-band followed him. Immediately upon approaching the $\mathrm{O}$ flats, he did a play bow (Way et al. 2006) to initiate play from the two pups. The pups immediately responded by chasing him and he, like Mange-back on the sand mound, stayed contained within a localized area (the $\mathrm{O}$ flats) instead of running from the pups as he sometimes did to get away from them. In other words, it was obvious during this particular observation that he was purposefully playing with the pups.

For the next $10 \mathrm{~min}$, Sill engaged in vigorous bouts of play chasing with groups of two to three pups at a time, after the other three pups returned to the area as well. The action occurred quickly, but I believe that 
he played with all five pups by the end of the session as pups were constantly changing directions and conspecifics with which they interacted. I could easily see Sill's tail wagging and his mouth open and relaxed, similar to the pups when they played. By 20:40 it was nearly dark and becoming difficult for me to see, but at this point all of the Coyotes gradually diminished their activity except for White-band which did not engage in play on that particular night. He often babysat the pups during summer 2007 and may have felt the need to watch them instead (although I did observe him $\geq 4$ times playing with the pups that summer).

At 20:42 Sill trotted at a steady pace southwest on a canal separating the east and central bog, leaving the pups at the $\mathrm{O}$ flats area. When he got to the south edge of the canal ( $200 \mathrm{~m})$ he approached the north edge of a private property that has a ca. $40 \mathrm{~kg}$ Labrador/ Golden retriever Domestic Dog mix ("Kota") with which he commonly interacted (by growling and barking at each other, usually from opposite sides of the bogs) south of the southeastern part of the central bog. When Sill approached the edge of Kota's yard (Kota was not outside) he sniffed then raised-leg urinated on a bush followed by a ground-scratch, common behavior I observed from him when marking his territory. He then proceeded to trot west at the south part of the bog complex, displaying a noticeably different and more serious disposition than when he was playing with the pups. He kept his tail at a $45^{\circ}$ angle and was very alert and tense on his route west. At 20:44, Mange-back and White-band left the pups and trotted through the central bog in the general (southwest) direction of Sill, but taking a more northerly counterclockwise route, likely to avoid Kota. All three adults gradually made their way to the south part of the west bog west of Bog Road and eventually became too difficult to see at 20:48. Sill's signal (at 20:58) indicated that he continued south, crossed a secondary road (River Road), and went to the south of the two cranberry bog rendezvous sites (detailed in Way 2003). Meanwhile, the pups remained around the $\mathrm{O}$ flats, eventually heading northeast into the wooded patch where they commonly rested and hid. I departed the area at 20:50 at dark.

\section{Discussion}

This Coyote social group behaved in a remarkably friendly manner toward one another and similar to what has been described for Wolves, other than that they preyed on small animals (rodents, rabbits), trash and other human food, and domestic cats (J. Way, unpublished data) rather than large ungulates (see Mech et al. 1998; Mech and Boitani 2003). In fact, it was obvious to me that the Coyotes, including adults, were having fun when they played, as demonstrated by such characteristics as a play face, tail-wagging, and/or engaging in affiliative activities which have been purported as nothing but play (Bekoff 1972a, 1974b;
Packard 2003; Way et al. 2006). Such canid play characteristics are obvious and recognizable to dog owners when their pet dogs are playing.

Bekoff (1999) claimed that social play may provide more promising evidence of animal minds than research in many other areas, for it may yield clues about the ability of animals to understand one another's intentions. While watching Sill, it was difficult for the pups (and for me as an observer) to misinterpret Sill's intentions from play bowing to initiate play, to a more serious (tail at $45^{\circ}$ angle) posture when he departed for his nightly travels (when none of the pups attempted to follow him). It is highly likely that the success of this social unit was predicated on the stability of the pack members, mainly Sill and Mangeback. By being mature older adults and extremely familiar with the area (see Way 2007*), these two Coyotes were never observed getting challenged by their younger, less experienced offspring.

This particular area (i.e., the open cranberry bog complexes) has produced some memorable Coyote sightings, including observations of Coyote pups for 11 years in a row (1997-2007: see Way 2003, 2007*). However, I do not believe this group to be the exception to the norm. Other packs in my study area, although less visible on the average, have similar social units and were occasionally observed in comparable amiable scenarios where adults were seen playing with one another (e.g., see Way 2001* and Way 2007*). Many of these observations of friendliness/play included older adults (usually radio-collared) which, like Sill, probably provided stability and experience to their pack. The eastern Coyote's family-oriented nature cannot be understated. In one instance, I have even observed two adults in a Coyote pack raising pups when an older, breeding female was killed when the pups were young (Way 2004).

Due to its success, the Coyote is typically maligned by the public and is often treated as vermin or pests by state wildlife agencies and/or animal control/pest agencies (Way 2007*). However, Coyotes are highly social, family-oriented, caring animals (Camenzind 1978; Bekoff and Wells 1980; Gese et al. 1996; Crabtree and Sheldon 1999;) that probably even enjoy life and each other (Way 2007*; this study). Once thought to be too subjective, there is a growing body of literature that supports this statement (e.g., see Bekoff 2002, 2007), and data from this paper regarding this one pack studied over eight years (2000 to 2007), provides irrefutable corroboration of Coyote sociality, including amiable/affiliative behaviors such as play.

\section{Acknowledgments}

I thank my family (especially my wife Tara), Marie Thomas, Eric Strauss and Boston College, and Barnstable High School for helping me with various aspects of my research. Two anonymous reviewers provided helpful comments. 
Documents Cited (marked * in text)

Cape Cod Commission. 1998. Cape trends: demographic and economic characteristics and trends. Cape Cod Commission, Barnstable, Massachusetts.

Way, J. G. 2001. The eastern coyote: documenting the habits of one of Cape Cod's newest residents. Conservation Perspectives, the online journal of the New England Chapter of the Society for Conservation Biology. http://www.nescb. org/epublications/spring2001/coyotes.html.

Way, J. G. 2007. Suburban howls: Tracking the eastern coyote in urban Massachusetts. Dog Ear Publishing, Indianapolis, Indiana.http://www.easterncoyoteresearch.com.

\section{Literature Cited}

Bekoff, M. 1972a. The development of social interaction, play, and metacommunication in mammals: an ethological perspective. Quarterly Review of Biology 47: 412-434.

Bekoff, M. 1972b. An ethological study of the development of social interactions in canids: a dyadic analysis. Ph.D. dissertation, Washington University, St. Louis, Missouri.

Bekoff, M. 1974a. Social play and play-soliciting by infant canids. American Zoologist 14: 323-340.

Bekoff, M. 1974b. Social play in coyotes, wolves, and dogs. BioScience 24: 225-230.

Bekoff, M. 1978. Behavioral development in coyotes and eastern coyotes. Pages 97-126 in Coyotes: biology, behavior and management. Edited by M. Bekoff. Blackburn Press, Caldwell, New Jersey.

Bekoff, M. 1989. Behavioral development of terrestrial carnivores. Pages 89-124 in Carnivore behavior, ecology, and evolution. Edited by J. L. Gittleman. Comstock Publishing Associates, Cornell University Press, Ithaca, New York.

Bekoff, M. 1999. Social cognition: exchanging and sharing information on the run. Erkenntnis 51: 113-128.

Bekoff, M. 2002. Minding animals: awareness, emotions, and heart. Oxford University Press, New York, New York.

Bekoff, M. 2007. The emotional lives of animals: A leading scientist explores animal joy, sorrow, and empathy -- and why they matter. New World Library, Novato, California.

Bekoff, M., and M. C. Wells. 1980. The social ecology of coyotes. Scientific American 242: 130-148.

Camenzind, F. J. 1978. Behavioral ecology of coyotes on the national elk refuge, Jackson, Wyoming. Pages 267-294 in Coyotes: biology, behavior and management. Edited by M. Bekoff. Blackburn Press, Caldwell, New Jersey.

Crabtree, R. L., and J. W. Sheldon. 1999. The ecological role of coyotes on Yellowstone's Northern Range. Yellowstone Science 7: 15-24.

Ewer, R. F. 1973. The carnivores. Cornell University Press, Ithica, New York.

Gese, E. M., R. L. Ruff, and R. L. Crabtree. 1996. Social and nutritional factors influencing the dispersal of resident coyotes. Animal Behaviour 52: 1025-1043.
Lehner, P. N. 1978. Coyote communication. Pages 127-162 in Coyotes: biology, behavior and management. Edited by M. Bekoff. Blackburn Press, Caldwell, New Jersey.

Martin, P., and P. Bateson. 1986. Measuring behavior. Cambridge University Press, New York, New York.

Mech, L. D. 1997. The Arctic wolf: ten years with the pack. Voyageur Press, Stillwater, Minnesota.

Mech, L. D., L. G. Adams, T. J. Meier, J. W. Burch, and B. W. Dale. 1998. The wolves of Denali. University of Minnesota Press, Minneapolis, Minnesota.

Mech, L. D., and L. Boitani. Editors. 2003. Wolves: behavior, ecology, and conservation. University of Chicago Press, Chicago, Illinois

Ortega, J. C. 1988. Activity patterns of different-aged coyote (Canis latrans) pups in southeastern Arizona. Journal of Mammalogy 69: 831-835.

Packard, J. M. 2003. Wolf behavior: Reproductive, social, and intelligent. Pages 35-65 in Wolves: Behavior, ecology, and conservation. Edited by L. D. Mech and L. Boitani, University of Chicago Press, Chicago, Illinois.

Rennicke, J. 2007. Playing around. National Parks. Summer 2007, pages 16-17.

Springer, J. T. 1979. Some sources of bias and sampling error in radio triangulation. Journal of Wildlife Management 43: 926-935.

Way, J. G. 2003. Descriptions and possible reasons for an abnormally large group size of adult eastern coyotes observed during summer. Northeastern Naturalist 10: 335-342.

Way, J. G. 2004. Survival of 8-week-old wild eastern coyote pups following the death of their mother. Northeast Wildlife 58: 66-71.

Way, J. G., P. J. Auger, I. M. Ortega, and E. G. Strauss. 2001. Eastern coyote denning behavior in an anthropogenic environment. Northeast Wildlife 56: 18-30.

Way, J. G., I. M. Ortega, and P. J. Auger. 2002a. Eastern coyote home range, territoriality and sociality on urbanized Cape Cod, Massachusetts. Northeast Wildlife 57: 1-18.

Way, J. G., I. M. Ortega, P. J. Auger, and E. G. Strauss. 2002b. Box-trapping eastern coyotes in southeastern Massachusetts. Wildlife Society Bulletin 30: 695-702.

Way, J. G., I. M. Ortega, and E. G. Strauss. 2004. Movement and activity patterns of eastern coyotes in a coastal, suburban environment. Northeastern Naturalist 11: 237254.

Way, J. G., and E. G. Strauss. 2004. Old-aged coyote in an urbanised landscape. Canid News 7.2: http://www.canids. org/canidnews/7/Old_aged_coyote.pdf.

Way, J. G., D.-L. M. Szumylo, and E. G. Strauss. 2006. An ethogram developed on captive Eastern Coyotes, Canis latrans. Canadian Field-Naturalist 120: 263-288.

Received 28 August 2007

Accepted 25 July 2008 